\section{Fortification of flour with folic acid is an overdue public health measure in the UK}

\author{
David Walker
}

The MRC Vitamin Study Research Group randomised control trial published in $1991^{1}$ was the first clear demonstration that folic acid supplementation at the time of conception significantly reduces the probability of neural tube defects. Of course, mandatory supplementation of flour is only one of the possible approaches to increasing folate levels in women of childbearing age but with the high rate of pregnancies that are not planned, it is difficult to enable women to ensure that their folic acid levels are high at the time of conception using other forms of supplementation. Promotion of voluntary uptake of folate supplements has been of limited effectiveness and uptake tends to be poor in lower socioeconomic groups, who potentially have the most to gain from supplementation. Mandatory supplementation of flour with folic acid has been adopted as the preferred public health measure for the prevention of neural tube defects in many countries.

Since 1991, mandatory folic acid fortification has been introduced in more than 70 countries including the USA, Canada and Australia with remarkable success. We now have substantial evidence that this practice is both effective and safe. In those countries using folic acid supplementation, the incidence of neural tube defects has decreased whereas in the UK the incidence has not decreased and indeed may now be increasing. The benefits are not limited to health gain. The healthcare cost savings from supplementation are substantial. The safety profile of supplementation is now much better understood as more countries adopt the measure. Meta-analyses of folic acid supplementation programmes using doses much higher than those proposed for the UK have not shown any adverse effect on the incidence of site-specific cancers or cardiovascular disease, which have been

Correspondence to Professor David Walker, University Hospitals of Morecambe Bay, Westmorland General Hospital, Burton Road, Kendal, Cumbria LA9 7RG, UK; david.walker@mbht.nhs.uk raised as concerns in the past. Concerns that folate supplementation might mask vitamin $\mathrm{B}_{12}$ deficiency and allow neurological progression have not been realised following the introduction of mandatory supplementation with folic acid. ${ }^{2}$

A new study by Morris et $a l^{3}$ draws attention to the opportunity lost in the UK since the value of folate supplementation was identified in 1991 to prevent neural tube defects in the UK. Our failure to address this public health issue has resulted in potentially $>2000$ preventable neural tube defects in pregnancy. This is consistent with changes in incidence following the introduction of mandatory supplementation in other countries such as the USA. ${ }^{4}$

Mandatory folic acid supplementation of flour in the UK was recommended by the Royal College of Obstetricians and Gynaecologists (RCOG) in 1997. This position was supported in 2000 by the Committee on Medical Aspects of Food and Nutrition Policy. The recommendation was refined but supported by the Scientific Advisory Committee for Nutrition (SACN) in 2006 and again in 2009. SACN also recommended a corresponding reduction in voluntary supplementation in commercial foodstuffs to avoid excessive intake. Mandatory supplementation was also recommended by the Food Standards Agency in 2007. To date, no UK government has been willing to put forward legislation to mandate folic acid supplementation. A private member's bill is currently being sponsored but the likelihood of success is low.

A further ironic development is that there is now evidence that commercial food manufacturers are beginning to reduce the levels of voluntary supplementation with folic acid, possibly in fulfilment of part of the SACN recommendations which, in the absence of mandatory supplementation of flour, may actually worsen the folate status of the population and increase the incidence of neural tube defects.

It is a recurring feature of UK public health policy that even when clear evidence of the safety and effectiveness of a public health intervention has been demonstrated through high quality research and review by expert bodies, recommendations for policy change are slow to be enacted. There are many examples in the UK of lost opportunities to address many preventable health risks including the delays in the limitation of smoking in public places, the slow implementation of preventive measures for venous thromboembolism in hospitals and the failure to extend the implementation of water fluoridation.

Once again the UK, having played a leading role in identifying the public health risk and the potential solution, is measuring the consequences of inaction at home, while other countries have taken a more proactive approach and are instead measuring the extent of their success. It is now 24 years since the problem was first clearly identified and 18 years since the Scientific Advisory Committee of the RCOG advised mandatory supplementation of flour. It is disappointing that despite overwhelming supporting evidence, we still have not found the courage to introduce this measure.

\section{Competing interests None declared.}

Provenance and peer review Commissioned; internally peer reviewed.

To cite Walker D. Arch Dis Child 2016;101:593.

Received 16 December 2015

Revised 5 February 2016

Accepted 14 February 2016

Published Online First 1 March 2016

\section{Linked}

http://dx.doi.org/10.1136/archdischild-2015-309226

Arch Dis Child 2016;101:593.

doi:10.1136/archdischild-2015-309983

\section{REFERENCES}

1 MRC Vitamin Study Research Group. Prevention of neural tube defects: results of the Medical Research Council Vitamin Study. Lancet 1991;338 131-7.

2 Mills JL, von Kohorn I, Conley MR, et al. Low vitamin B-12 concentrations in patients without anaemia: the effect of folic acid fortification of grain. Am J Clin Nutr 2003:77:1474-7.

3 Morris JK, Rankin J, Draper ES, et al. Prevention of neural tube defects in the UK: a missed opportunity. Arch Dis Child 2016;101:604-7.

4 Williams J, Mai CT, Mulinare J, et al. Updated estimates of neural tube defects prevented by mandatory folic Acid fortification-United States, 1995-2011. MMWR Morb Mortal Wkly Rep 2015;64:1-5 